\title{
Zur 25 jährigen Wiederkehr des Todestages von Fritz Schaudinn
}

Am 22. Juni dieses Jahres sind 25 Jahre verflossen, seitdem der geniale Protozoologe und Entdecker der Syphiliespirochäte Fritz Schaudinn einer tücki-schen Krankheit im Alter von kaum 35 Jahren erlegen ist. Seine unsterbliehen Verdienste um die Protozoenkunde sind zur 25. Wiederkehr der Entdeckung der Spir. pall, eingehend gewürdigt und durch die Einrichtung des Schaudinn-Gedächtniszimmers im Zoologischen Institut der Universität Berlin gekrönt

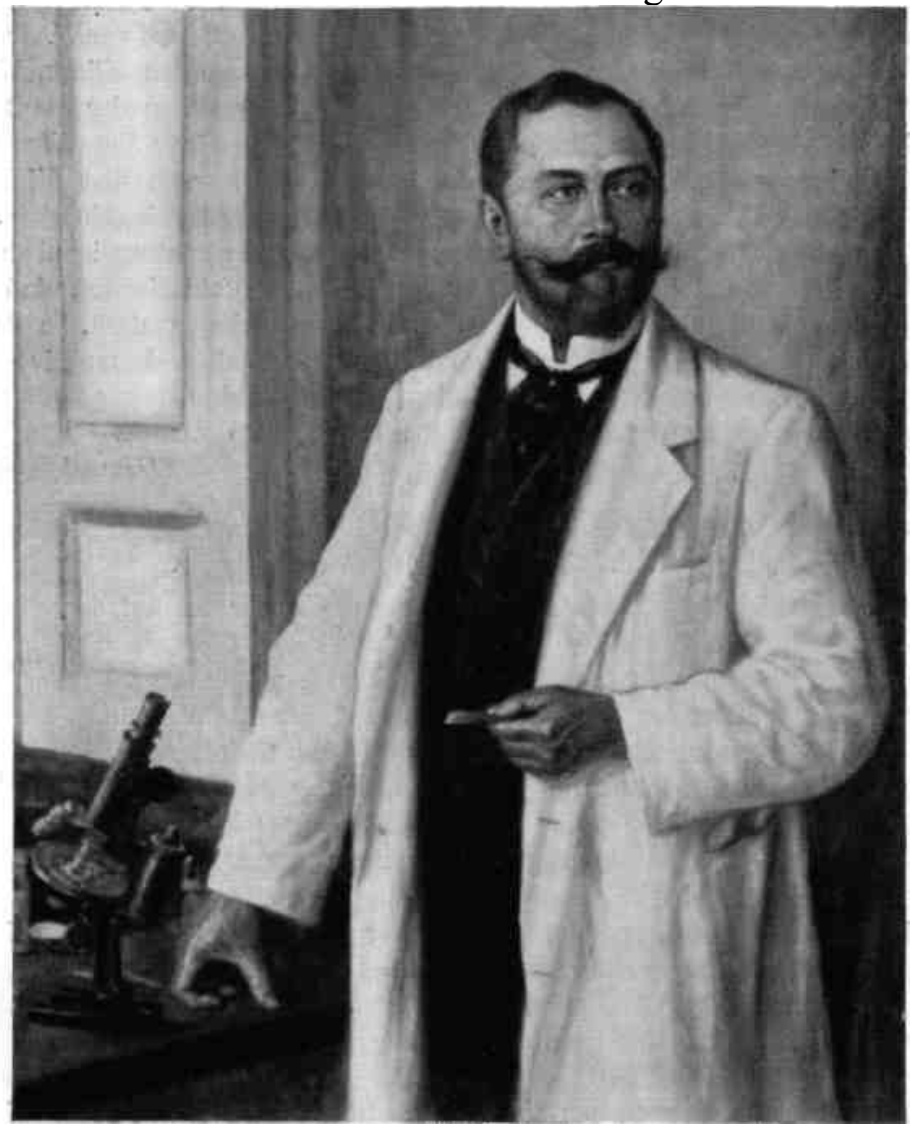

worden. Auf die bei dieser G-elegenheit gehaltenen Ansprachen, besonders die von Prof. Hartma·nn, kann daher hier verwiesen werden1). Die Bronzeplakette, die von Dr. Menser-Bonn entworfen und im Sehaudinn-Gedächtniszimmer auf-gehängt worden ist, konnte von diesem vortrefflichen Gelehrten kein vollkom-menes Bild geben, ebensowenig die Photographien, die von ihm erhalten sind. Es ist daher sehr zu begrüßen, daß der Bonner Kunstmaler Wilh. Faßbender auf Anregung von Prof. Borgert und mir ein Ölbild Fritz Schauäinns gemalt hat, das in Lebensgröße, charakteristischer Haltung und trefflicher 
x) Auch ich habe Schauäinns in mehreren Artikeln gedacht (Dt. Med. Wschr. 1906. Nr. 27 und Derm. Ztschr. Bd. 34 (1921) und Bd. 59 (1930).

Personalien und Tagesnachrichten.

297

Farbtönung seine Persönlichkeit der. Nachwelt lebendig und getreu zu erhalten vermag. Das ausgezeichnete Gemälde ist, nachdem der Verlag Gustav Fischer in Jena, Prof. Borgert-Bonn und ich einen Teil der Kost'en ühernommen haben, von Prof. Hartmann für das Kaiser-WilhelmInstitut für Biologie in Berlin-Dahlem erworben worden.

So ist durch dieses wohlgelungene Gemälde, von dem die beigefügte $\mathbf{m P h o t o g r a p h i e}$ eine ungefähre Vorstellung gibt, ein alter Wünsch vieler Freunde • Fritz Schauäinns in schönster Weise erfüllt worden.

In unserer, auch große Leistungen leider so schnell vergessenden Zeit erscheint es mir besonders wichtig, dieses Märtyrers der Protozoenforschung, der ebenso wie seine Schüler v. Froivazek und Gonder, wo hi ein Opfer seiner Protozoen-Experimente geworden sein dürfte, dadurch zu gedenken, daß alle ihm nahestehenden wissenschaftlichen Vereinigungen und Forschungsinstitute zu sein.em:. 25jährigen Todestage auf seinem Grabe in Berlin einen Kranz niederlegen. Ich gebe mich der Hoffnung hin, daß diese Anregung, die ich man' besonders in Betracht kommende Gesellschaften und Institute des In-und Auslandes gegeben habe, Verständnis findet und dadurch die Dankbarkeit, die in unseren Herzen nie erlöschen darf, einen auch nach außen sichtbaren Ausdruck erhält. Als erste haben die Herren Professoren Boux und Calmette vom Institut Pasteur in Paris zugestimmt.

Eine besonders schöne Ehrung würde es bedeuten, Wenn es gelänge, anläßlich dieses, wehmütige Erinnerungen herauf beschwörenden Tages trotz.der wirtschaftlichen Not, in der wir uns jetzt befinden, einen Schaudinn-Forschungsfonds ir $\cap$ In- und Ausland zu sammeln. Dank dem Entgegenkommen einiger Freunde, die die Nennung ihres Namens nicht wünschen, vermag ich selbst hierfür die Summe von 1000 Mark zu zeichnen. Weitere Beträge wird die Schriftleitung gern entgegennehmen; es wird gebeten sie auf meinen Namen an die Deutsche Bank, Filiale Bonn a. Rh. (Separatkonto Forschungs-fonds) oder auf mein Postscheckkonto (23651 Köln) überweisen zu wollen.

Prof. E. Hoffmann (Bonn).

Personalien und Tagesnachrichten.

Prof. Br. Bloch-Züvich hat nach langdauernden Verhandlungen den Ruf an die Universität Berlin als Nachfolger von Prof. Arndt abgelehnt, da seine Forderungen nicht bewilligt wurden.

Prof. Bering, Chefarzt der Dermatologischen Abteilung an den Städtischen Krankenanstalten in Essen, hat einen Ruf an die Universität Köln als Nachfolger von Prof. Zinsser erhalten.

Dr. Erich Uhlmann in Freiburg hat sich für Dermatologie habilitiert, ebenso Dr. Sebastian Szathmary in Pecs (Fünfkirchen).

Prof. Bos $\underset{j}{-}$-Freiburg ist von der Britischen Dermatologischen Gesellschaft aufgefordert worden, auf ihrem diesjährigen Kongreß in Bristol am 2. und 3. Juli einen Vortrag zu halten und wird dieser Einladung Folge leisten.

Prof. A. Jordan-Moskau wurde zum korrespondierenden Mitglied der dänischen dermatologischen Gesellschaft ernannt.

Prof. C. Bruck, Leiter der Dermatologischen Abteilung des Kranken-hauses Altona, hielt in der Berliner medizinischen Gesellschaft anläßlich des 25jährigen Bestehens der Serodiagnose der. Syphilis einen Festvortrag. Die Berliner Dermatológische Gesellschaft wäblte ihn aus diesem Anlaß zum Ehren-mitglied. 